\title{
Utilization of systemic inflammatory response syndrome criteria in predicting mortality among geriatric patients with influenza in the emergency department
}

\author{
Henry Chih-Hung Tai ${ }^{1}$, Chien-Chun Yeh ${ }^{1}$, Yen-An Chen ${ }^{1}$, Chien-Chin Hsư ${ }^{2,3}$, Jiann-Hwa Chen ${ }^{1,4}$, Wei-Lung Chen ${ }^{1,4}$,
} Chien-Cheng Huang ${ }^{2,5,6}$ and Jui-Yuan Chung ${ }^{\text {* }^{*}}$

\begin{abstract}
Background: Systemic Inflammatory Response Syndrome (SIRS) criteria are often used to evaluate the risk of sepsis and to identify in-hospital mortality among patients with suspected infection. However, utilization of the SIRS criteria in mortality prediction among geriatric patients with influenza in the emergency department (ED) remains unclear. Therefore, we conducted a research to delineate this issue.

Methods: This is a retrospective case-control study including geriatric patients (age $\geq 65$ years) with influenza, who presented to the ED of a medical center between January 1, 2010 and December 31, 2015. Vital signs, past history, subtype of influenza, demographic data, and outcomes were collected from all patients and analyzed. We calculated the accuracy for predicting 30-days mortality using the SIRS criteria. We also performed covariate adjustment of the area under the receiver operating characteristic curve (AUROC) via regression modeling.

Results: We recruited a total of 409 geriatric patients in the ED, with mean age 79.5 years and an equal sex ratio. The mean SIRS criteria score was $1.9 \pm 1$ 1.1. The result of a Hosmer-Lemeshow goodness-of-fit test was 0.34 for SIRS criteria. SIRS criteria score $\geq 3$ showed better mortality prediction, with odds ratio (OR) 3.37 (95\% confidence interval (CI), 1.05-10.73); SIRS score $\geq 2$ showed no statistical significance, with $p=0.85(\mathrm{OR}, 1.15 ; 95 \% \mathrm{Cl}, 0.28-4.69)$. SIRS score $\geq 3$ had acceptable 30-days mortality discrimination, with AUROC $0.77(95 \% \mathrm{Cl}, 0.68-0.87)$ after adjustment. SIRS score $\geq 3$ also had a notable negative predictive value of 0.97 ( $95 \% \mathrm{Cl}, 0.94-0.99)$.
\end{abstract}

Conclusion: The presence of a higher number of SIRS criteria $(\geq 3)$ showed greater accuracy for predicting mortality among geriatric patients with influenza.

Keywords: Death, Emergency department, Geriatric, Influenza, Mortality, Prediction, SIRS criteria

\section{Background}

Influenza is a seasonal disease occurring typically in winter periods. It is highly contagious and spread via airborne or respiratory transmission. During the epidemic season, emergency departments (EDs) may be overwhelmed by patients with influenza. The illness tends to be most severe among elderly people, nursing home residents, infants, young children, and

\footnotetext{
*Correspondence: bybarian@gmail.com

'Department of Emergency Medicine, Cathay General Hospital, Taipei, Taiwan

Full list of author information is available at the end of the article
}

immunocompromised individuals [1]. When illness is associated with complications of pulmonary, cardiovascular, and less frequently, neuromuscular diseases, hospitalization is often required [2]. In the United States, it is estimated that 142,000 hospitalizations are related to influenza infection [3], and approximately 568,000 patient admissions were among elderly adults (age $\geq 65$ years) [4]. Furthermore, more than $90 \%$ of mortality and complications of influenza occur in elderly patients [3]. Therefore, to most efficiently utilize medical resources, an effective clinical tool is needed

(c) The Author(s). 2019 Open Access This article is distributed under the terms of the Creative Commons Attribution 4.0 International License (http://creativecommons.org/licenses/by/4.0/), which permits unrestricted use, distribution, and reproduction in any medium, provided you give appropriate credit to the original author(s) and the source, provide a link to the Creative Commons license, and indicate if changes were made. The Creative Commons Public Domain Dedication waiver (http://creativecommons.org/publicdomain/zero/1.0/) applies to the data made available in this article, unless otherwise stated. 
to predict the severity of influenza infection among geriatric patients.

The SIRS criteria was initially used as a clinical tool to identify the risk of sepsis and to predict in-hospital mortality. It was first introduced in 1992 by the American College of Chest Physicians (ACCP) and Society of Critical Care Medicine (SCCM) Consensus Conference committee to define sepsis [5]. It is a scoring system, with calculation based on a collection of clinical signs and laboratory investigations that reflect the host inflammatory response, including heart rate $>90$ beats per minute, respiratory rate $>20$ breaths per minute, body temperature $<36{ }^{\circ} \mathrm{C}$ or $>$ $38^{\circ} \mathrm{C}$, White blood cell (WBC) count $<4000 / \mathrm{mm}^{3}$ or $>12,000 / \mathrm{mm}^{3}$ and band form $>10 \%$. Patients who meet two or more of the SIRS criteria fulfil the definition of SIRS.

Influenza infection may cause a severe inflammatory response, characterized by high fever, muscle soreness [6], and associated symptoms and signs of tachycardia and tachypnea, which are all the variables of SIRS criteria. Although SIRS criteria is no longer the definition of sepsis after the Third International Consensus Definitions for Sepsis and Septic Shock (Sepsis-3), utilization of SIRS criteria in predicting mortality among geriatric patients with influenza has never been investigated. We conducted a keyword search using the terms "death", "geriatric", "influenza", "mortality", "prediction", and "SIRS criteria" in PubMed and Google Scholar; however, we found no relevant studies regarding this topic. Therefore, we conducted the present study to delineate the issue.

\section{Methods}

\section{Study design, setting, and participants}

This study was performed at a 800-bed university-affiliated medical center in Taipei, the capital city of Taiwan. Approximately 55,000 patients present to the study ED each year [7], where they are cared for by board-certified emergency physicians. About 33\% of these ED patients are elderly adults [8, 9]. In our study, we recruited geriatric patients (age $\geq 65$ years) who presented to the ED between January 1, 2010 and December 31, 2015, and who fulfilled the following conditions: (1) tympanic temperature $(\mathrm{TM}) \geq$ $37.2^{\circ} \mathrm{C}$ or an increase in baseline $\mathrm{TM} \geq 1.3^{\circ} \mathrm{C}[8,9]$, and (2) influenza infection defined as a positive influenza pharyngeal or throat swab test using pharyngeal or throat swab test (de antigen detection) [10].

\section{Definition of variables and primary outcome}

SIRS criteria are defined as heart rate $>90$ beats per minute, respiratory rate $>20$ breaths per minute, temperature $<36^{\circ} \mathrm{C}$ or $>38^{\circ} \mathrm{C}$, WBC count $<4000 /$ $\mathrm{mm}^{3}$ or $>12,000 / \mathrm{mm}^{3}$ and band form $>10 \%$ [5]. The
SIRS criteria score will be calculated and obtained while arriving at the ED. Sepsis is defined according to the sepsis-3 campaign. Infected patients with total Sequential Organ Failure Assessment (SOFA) score $\geq 2$ points are considered as sepsis. Patients who survived at least 30 days (since arriving at the ED) were considered "survivors" in this analysis [11, 12]. Telephone follow-up was used to ascertain 30-day survival if the patient was discharged from the hospital in less than 30 days.

\section{Data collection and assignment to case and control groups}

A retrospective chart review method was used to obtain data of geriatric patients in the ED who fulfilled the criteria of influenza infection. Patients' vital signs, demographic characteristics, influenza subtype, laboratory data, past medical history, admission, and 30-day mortality data were collected by an emergency physician. Finally, 479 geriatric ED patients met the criteria of influenza infection. After excluding 70 patients who were lost to follow up, had insufficient data, or transferred patients who had been treated at other hospitals, a total 409 patients were finally included. The included patients were categorized into either the survival and the mortality group, based on their 30-day outcome. All variables were compared between the two groups.

\section{Ethical statement}

This study was approved by the Institutional Review Board of Cathay General Hospital and conducted according to the Declaration of Helsinki. Because this was an observational study, the need for informed consent from patients was waived.

\section{Statistical analysis}

Statistical analysis was performed using SPSS 23.0 for Mac (SPSS Inc., Chicago, IL, USA). The statistical power of this study size (409 patients) was adequate for 0.80 , calculated via G-power 3.0. Continuous data are presented as means \pm standard deviation (SD). We used an independent samples $t$-test, or the Mann-Whitney-Wilcoxon test for continuous variables in the univariate analyses. Pearson's chi-square test or Fisher's exact test was used for categorical variables. We dichotomized SIRS criteria to less than 1 and 1 or more; less than 2 and 2 or more; less than 3 and 3 or more. Logistic regression was then performed to evaluate 30-days mortality prediction among each dichotomized SIRS criteria group ( $p$ value $<0.05)$. The area under the receiver operating characteristic curve (AUROC) was used to evaluate mortality discrimination ability. AUROCs were further adjusted for comorbidities that affect mortality ( $p$ value $<0.1)$ in regression modeling. The Hosmer- 
Lemeshow goodness-of-fit test was performed to evaluate the reliability of the scoring system. Sensitivity, specificity, positive predictive value (PPV), and negative predictive value (NPV) were also analyzed.

\section{Results}

A total 409 patients were included in this study. The 30day mortality rate was $4.9 \%(20 / 409)$ (Table 1$)$. The percentages of the two sexes were equal, and mean patient age \pm SD was $79.5 \pm 8.3$ years. The mean \pm SD of systolic blood pressure, heart rate, body temperature, respiratory rate, Glasgow coma scale, and WBC count were $146.1 \pm 30.5 \mathrm{mmHg}, 98.8 \pm 20.5$ beats $/ \mathrm{min}, 38.18 \pm$ $0.93^{\circ} \mathrm{C}, 21.3 \pm 4.2$ per minute, $13.9 \pm 2.3$, and $10,590.0 \pm$ 5820.0, respectively. Higher prevalence of cancer was noted in the mortality patient group whereas there was a

Table 1 Characteristics of geriatric patients with influenza in the emergency department

\begin{tabular}{|c|c|c|c|c|}
\hline Characteristics & Total patients $(n=409)$ & Mortality $(n=20)$ & Survival $(n=389)$ & $p$ Value \\
\hline Male sex & $205(50.1)$ & $13(65.0)$ & $192(49.3)$ & 0.17 \\
\hline Age, years & $79.5 \pm 8.3$ & $81.2 \pm 8.5$ & $79.5 \pm 6.4$ & 0.36 \\
\hline \multicolumn{5}{|l|}{ Age subgroup } \\
\hline Young elderly (65-74 yr) & $125(30.6)$ & $4(20.0)$ & $121(31.1)$ & 0.31 \\
\hline Moderately elderly (75-84 yr) & $174(42.5)$ & $10(50.0)$ & $164(42.1)$ & 0.51 \\
\hline Old elderly ( $\geq 85 \mathrm{yr}$ ) & $110(26.9)$ & $6(30.0)$ & $104(26.8)$ & 0.76 \\
\hline \multicolumn{5}{|l|}{ Vital signs } \\
\hline Respiratory rate (per minute) & $21.3 \pm 4.2$ & $23.4 \pm 7.5$ & $21.1 \pm 3.9$ & 0.02 \\
\hline Glasgow's coma scale & $13.9 \pm 2.3$ & $12.0 \pm 4.0$ & $14.1 \pm 2.2$ & 0.03 \\
\hline $\mathrm{SBP}(\mathrm{mmHg})$ & $146.1 \pm 30.5$ & $135.1 \pm 31.2$ & $146.7 \pm 30.5$ & 0.28 \\
\hline Body temperature ( ${ }^{\circ} \mathrm{Celsius)}$ & $38.18 \pm 0.93$ & $38.19 \pm 0.92$ & $38.17 \pm 0.93$ & 0.38 \\
\hline Heart rate (beats/min) & $98.8 \pm 20.5$ & $103.0 \pm 21.6$ & $98.6 \pm 20.5$ & 0.55 \\
\hline \multicolumn{5}{|l|}{ Past history } \\
\hline Cancer & $61(14.9)$ & $7(35)$ & $54(13.9)$ & 0.02 \\
\hline COPD & $111(27.1)$ & $0(0)$ & $111(28.5)$ & 0.03 \\
\hline Hypertension & $263(64.3)$ & $17(85.0)$ & $246(63.2)$ & 0.06 \\
\hline Coronary artery disease & $103(25.1)$ & $10(50.0)$ & $93(23.9)$ & 0.09 \\
\hline Stroke & $65(15.9)$ & $4(20)$ & $61(15.7)$ & 0.63 \\
\hline Diabetes & $163(39.8)$ & $7(35.0)$ & $156(40.1)$ & 0.66 \\
\hline \multicolumn{5}{|l|}{ Laboratory data } \\
\hline WBC (cells $/ \mathrm{mm}^{3}$ ) & $10,590.0 \pm 5820.0$ & $14530.0 \pm 6.2$ & $10380.0 \pm 5.8$ & $<0.01$ \\
\hline Bandemia (band form > 10\%) & $43(10.2)$ & $7(35)$ & $36(9.2)$ & $<0.01$ \\
\hline CRP $(\mathrm{mg} / \mathrm{dL})$ & $8.2 \pm 10.1$ & $11.7 \pm 9.2$ & $8.03 \pm 10.2$ & 0.09 \\
\hline Platelet $\left(10^{3} / \mathrm{mm}^{3}\right)$ & $186.2 \pm 158.8$ & $198.9 \pm 140.3$ & $185.6 \pm 159.9$ & 0.68 \\
\hline SIRS & $1.91 \pm 1.1$ & $2.5 \pm 1.1$ & $1.9 \pm 1.1$ & 0.03 \\
\hline $\mathrm{SIRS} \geq 2$ & $258(63.1)$ & $16(80.0)$ & $242(62.2)$ & 0.11 \\
\hline $\operatorname{SIRS} \geq 3$ & $126(30.8)$ & $12(60.0)$ & $114(29.3)$ & $<0.01$ \\
\hline \multicolumn{5}{|l|}{ Influenza subtypes } \\
\hline Influenza A & $278(68.0)$ & $12(60)$ & $266(68.3)$ & 0.45 \\
\hline Influenza B & $120(29.3)$ & $5(25)$ & $115(29.5)$ & 0.67 \\
\hline Influenza A+B & $11(2.7)$ & $3(15)$ & $8(2.1)$ & $<0.01$ \\
\hline Influenza vaccination & $8(1.9)$ & $1(5)$ & $7(1.8)$ & 0.55 \\
\hline DNR & $4(0.98)$ & $2(10)$ & $2(0.5)$ & 0.08 \\
\hline Admission rate ${ }^{\dagger}$ & $343(83.9)$ & $20(100)$ & $323(83.0)$ & 0.05 \\
\hline
\end{tabular}

Data were presented as \% or Mean \pm SD. ED Emergency Department, SD standard deviation, SBP systolic blood pressure, COPD chronic obstructive pulmonary disease, WBC white blood cell count, CRP C-reactive protein, DNR don not rescue, SIRS Systemic Inflammatory Response Syndrome ${ }^{\dagger}$ Admission to general ward or intensive care unit 
lower prevalence of chronic obstructive pulmonary disease among patients in the survival group.

Laboratory data analysis showed that the mortality group tended to have a higher band form percentage and WBC count, and more coinfection (i.e., influenza $\mathrm{A}$ and $\mathrm{B}$ ) than the survival group. Antiviral drugs like oseltamivir or zanamivir are prescribed immediately, once influenza infection is diagnosed. Among the 20 patients in the mortality group, sepsis accounted for $70 \%$ of deaths (14 patients), respiratory failure for $15 \%$ (3 patients), and cardiovascular events accounted for $15 \%$ of deaths ( 2 patients with acute myocardial infarction and 1 patient with myocarditis). There was no statistical difference with respect to a "do not resuscitate" order between the mortality and survival groups.

The score distribution in geriatric patients with influenza infection, according to the number of SIRS criteria present, showed that 105 patients (25.7\%) met 1 criteria, 132 patients (32.3\%) met 2, and 92 patients met 3 criteria (Fig. 1). The mortality rate of patients scoring SIRS criteria $\geq 3$ was 9.5 , and $6.2 \%$ for scoring SIRS criteria $\geq 2$ (Fig. 2). SIRS criteria score $\geq 3$ showed better prediction of mortality, with OR 3.37 (95\% confidence interval (CI), 1.05-10.73) (Table 2); on the contrary, SIRS score $\geq 2$ showed no statistical significance, with $p$ value 0.85 (OR, $1.15 ; 95 \% \mathrm{CI}$, 0.28-4.69) (Table 2). The Hosmer-Lemeshow goodness-of-fit was 0.34 for SIRS criteria score $\geq 3$.

The AUROC, adjusted for coronary artery disease (CAD; $p=0.09)$ and cancer $(p=0.02)$, in predicting mortality showed that SIRS score $\geq 3$ (0.77; 95\% CI, 0.68 0.87 ) had acceptable discrimination ability (Table 2 ). The performance of SIRS score $\geq 3$ in predicting mortality among geriatric patients with influenza infection showed good specificity of 0.7 (95\% CI, 0.66-0.75) and NPV of 0.97 (95\% CI, 0.94-0.99) (Table 2).

\section{Discussion}

Although the new Sepsis-3 guideline no longer uses host inflammatory response syndrome criteria in the identification of sepsis and has eliminated the term severe sepsis [13], SIRS criteria are still useful in predicting the risk of organ dysfunction and mortality in patients with sepsis [13]. There are several articles discussing and debating the usefulness of SIRS criteria in prognosis prediction among adults in the ED and intensive care unit (ICU). Williams and colleagues carried out a large prospective database study at a tertiary Australian medical center, including 8,871 ED patients and aiming to determine the prognostic impact of SIRS criteria. In their research, those authors discovered that SIRS criteria were associated with an increased risk of organ dysfunction (relative risk 3.5) and mortality in patients without organ dysfunction (OR 3.2) [14]. Furthermore, a study in Greece analyzing 3346 patients with infection outside of the ICU and 1,058 patients with infection in the ICU showed that the quick sepsis-related organ failure (qSOFA) score has poorer sensitivity for early sepsis risk assessment than the SIRS criteria [15].

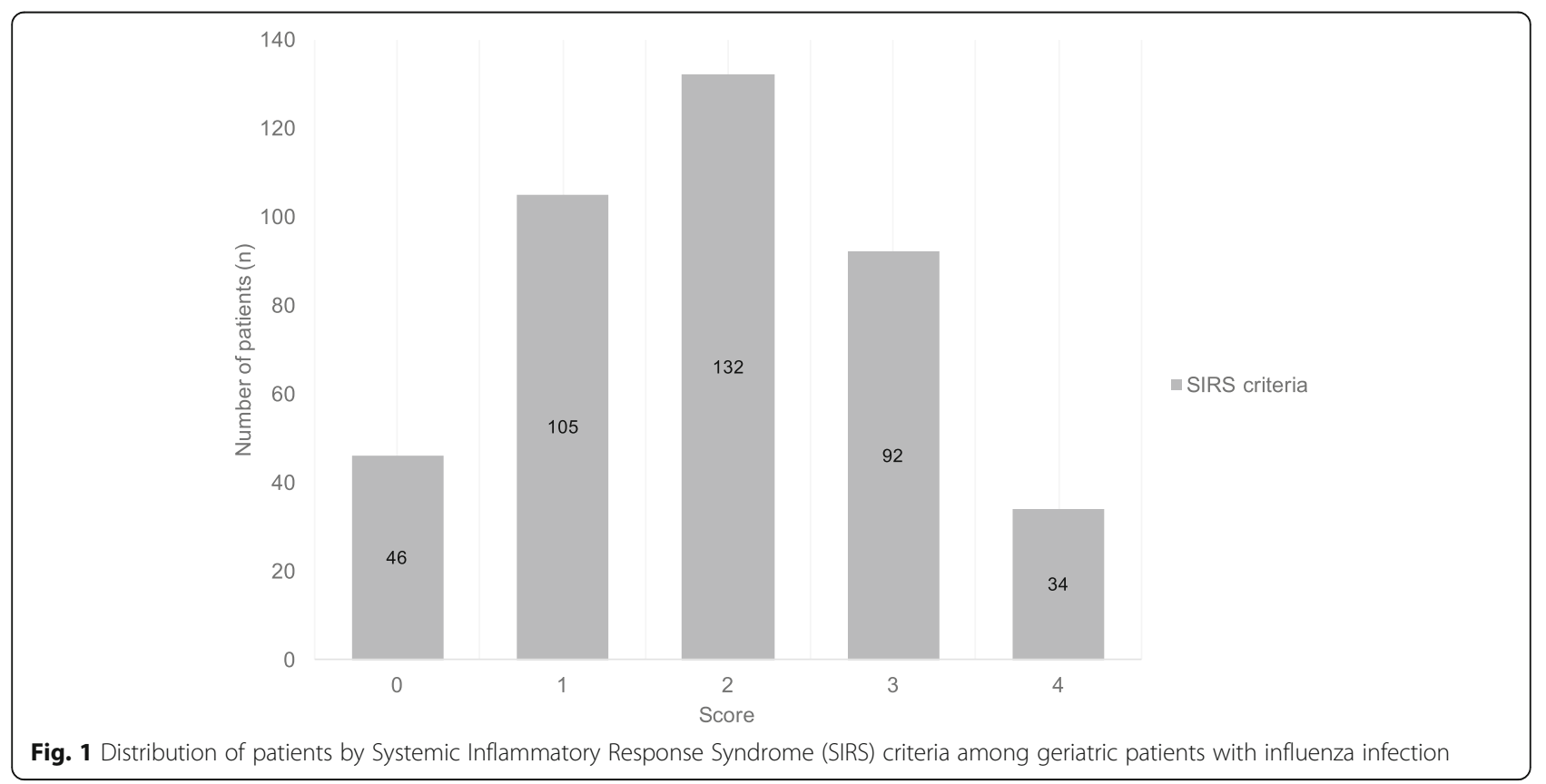




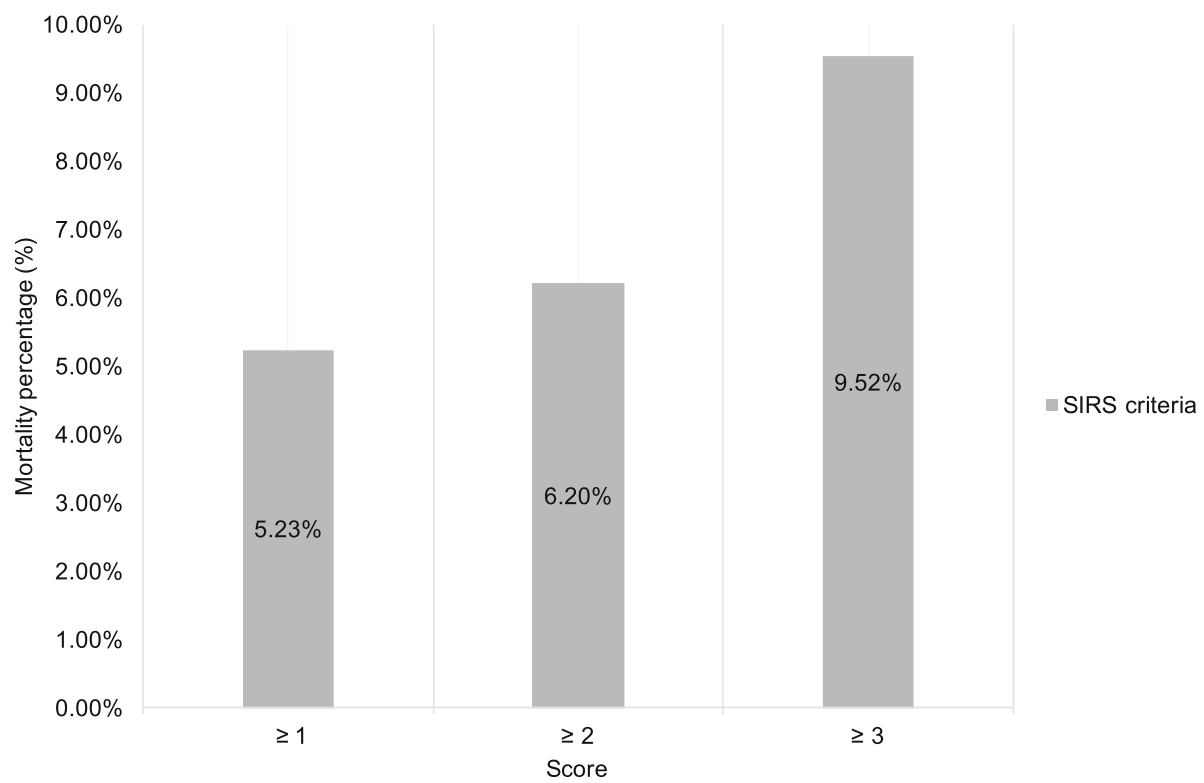

Fig. 2 Mortality by Systemic Inflammatory Response Syndrome (SIRS) criteria $\geq 1, \geq 2$ and $\geq 3$ among geriatric patients with influenza infection

In the present study, we discovered that SIRS criteria score $\geq 3$ was a better predictor of mortality among geriatric patients with influenza infection than SIRS score $\geq$ 2. Similar results were seen in some previous studies among patients with sepsis. A retrospective study of 680 hospitalized patients with bacteremia showed a similar result in that the prognostic sensitivity of SIRS score $\geq 2$ was lower than that of SIRS $\geq 3$ in elderly patients aged $\geq 85$ years [16]. Another ICU-based study in Greece also indicated that SIRS score $\geq 3$ was a better mortality predictor than SIRS score $\geq 2$ [15].

A possible reason for our finding is that geriatric patients with infection usually present with ambiguous initial symptoms due to a decreased physiological response $[17,18]$. Therefore, a family member or caregiver could easily overlook the patient's infection status, with a resulting delay in seeking medical attention until disease progression when the illness has become severe. In the present study, the mean duration from initial symptoms to time of ED arrival in geriatric patients with influenza was 3.56 days. Apparent physiological response was seen under this delayed ED arrival circumstances, with mean heart rate $>90$ beats per minute, mean body temperature $>38.0^{\circ} \mathrm{C}$, mean respiratory rate $>20$ per minute, and mean $\mathrm{WBC}$ count $>10,000 \mathrm{~mm}^{3}$ (Table 1).

We found that the sensitivity and specificity of SIRS score $\geq 3$ were $<80 \%$; however, SIRS $\geq 3$ had a notable NPV of $97 \%$, which may be useful in ruling out poor prognosis and mortality among geriatric patients with influenza [19]. Comorbidities such as CAD and cancer may affect mortality in geriatric patients with influenza infection [20]. Infection with influenza may aggravate underlying cardiac disease, deteriorate heart function, and increase the chance of myocardial infarction in patients with a past history of CAD [21]. Patients with a history of cancer may have undergone chemotherapy or radiation therapy, which may compromise the entire immune system, resulting in immunocompromised status and an increased risk of sepsis [22]. The AUROC was therefore adjusted for these comorbidities.

To our knowledge, this is the first study to report the utility of SIRS criteria in the prediction of mortality among geriatric patients with influenza. There were also some limitations to this study. First, as the study was

Table 2 Odds ratio, adjusted AUROC and performance of SIRS criteria $\geq 3$ in predicting mortality in geriatric patients with influenza infection

\begin{tabular}{|c|c|c|c|c|c|c|}
\hline \multirow{2}{*}{$\begin{array}{l}\text { SIRS } \\
\text { Criteria }\end{array}$} & Odds ratio & AUROC & Sensitivity & Specificity & PPV & NPV \\
\hline & $(95 \% \mathrm{Cl})$ & $(95 \% \mathrm{Cl})$ & $(95 \% \mathrm{Cl})$ & $(95 \% \mathrm{Cl})$ & $(95 \% \mathrm{Cl})$ & $(95 \% \mathrm{Cl})$ \\
\hline \multirow[t]{2}{*}{$S I R S \geq 3$} & 3.37 & 0.77 & 0.60 & 0.70 & 0.09 & 0.97 \\
\hline & $(1.05-10.73)$ & $(0.68-0.87)$ & $(0.36-0.80)$ & $(0.66-0.75)$ & $(0.05-0.16)$ & $(0.94-0.99)$ \\
\hline \multicolumn{3}{|c|}{ Hosmer and lemeshow goodness of fit } & 0.34 & & & \\
\hline
\end{tabular}

SIRS Systemic Inflammatory Response Syndrome, $\mathrm{Cl}$ confidence interval, AUROC area under the curve, AUROC adjusted by coronary artery disease and cancer, PPV positive predictive value, NPV negative predictive value 
conducted at a tertiary medical center, influenza disease severity may be more intense among our patient population. Second, some detailed patient information and data may be missing owing due to the study design, which was a retrospective chart review. Further external validation is needed to proof the findings of this study. Third, the diagnosis of influenza should be further confirmed using other advanced examinations, such as reverse transcription polymerase chain reaction, immunofluorescence assay, or viral culture, as the influenza swab test may yield false positive or false negative results. The PPV and NPV for influenza A were 85.7 and $89.8 \%$, and the PPV and NPV for influenza B were 66.7 and $93.9 \%$, respectively [23]. The method used in this study has the advantage of speed and simplicity, for research purposes. Fourth, patient selection according to a positive influenza test rather than a clinical diagnosis may result in underestimation of the actual number of geriatric patients with influenza in the 5-year study period. Patients who were clinically diagnosed with influenza but had a false negative influenza swab test result may have been overlooked and excluded from the study. The influenza swab test has a modest sensitivity of $58-67 \%$ and a high specificity of 98\% [24]. Fifth, subtypes of influenza virus were not specified, as different strains of influenza virus may result in different fatality rate [26]. Furthermore, specific factors that affect mortality in different strains of influenza virus should be evaluate too [27].

\section{Conclusion}

The presence of a higher score of SIRS criteria $(\geq 3)$ showed greater accuracy than SIRS $\geq 2$ for predicting mortality among geriatric patients with influenza. The high NPV of SIRS criteria $\geq 3$ makes it a useful tool to rule out poor prognosis and mortality in this patient population. Further research is needed to validate the findings of this study.

\begin{abstract}
Abbreviations
ACCP: American College of Chest Physicians; AUROC: Area under the receiver operating characteristic curve; CAD: Coronary artery disease; Cl: Confidence Interval; COPD: Chronic obstructive pulmonary disease; DNR: Do not rescue; ED: Emergency department; ICU: Intensive care units; NPV: Negative predictive value; OR: Odds ratio; qSOFA: Quick sepsis-related organ failure; SCCM: Society of Critical Care Medicine; SD: Standard deviation; SIRS: Systemic Inflammatory Response Syndrome; Third International Consensus Definitions for Sepsis and Septic Shock: Sepsis-3; TM: Tympanic temperature; WBC: White blood cell
\end{abstract}

\section{Acknowledgments}

Not applicable

\section{Authors' contributions}

CHT, CCY, YAC, JYC, CC Hsu and CC Huang, designed and conceived this study and wrote the manuscript. JYC performed the statistical analysis. JHC and WLC provided professional suggestions and wrote the manuscript. All authors read and approved the final manuscript.
Funding

This study received no specific funding.

\section{Availability of data and materials}

The datasets supporting the conclusions of this article are available from the corresponding author on reasonable request.

\section{Ethics approval and consent to participate}

The study was approved by the Institutional Review Board of Cathay General Hospital. Because this was an observational study, the need for informed consent from patients was waived.

\section{Consent for publication}

Not applicable.

\section{Competing interests}

The authors declare that they have no competing interests.

\section{Author details}

${ }^{1}$ Department of Emergency Medicine, Cathay General Hospital, Taipei, Taiwan. ${ }^{2}$ Department of Emergency Medicine, Chi-Mei Medical Center, Tainan, Taiwan. ${ }^{3}$ Department of Biotechnology, Southern Taiwan University of Science and Technology, Tainan, Taiwan. ${ }^{4} \mathrm{Fu}$ Jen Catholic University School of Medicine, Taipei, Taiwan. ${ }^{5}$ Department of Environmental and Occupational Health, College of Medicine, National Cheng Kung University, Tainan, Taiwan. ${ }^{6}$ Department of Senior Services, Southern Taiwan University of Science and Technology, Tainan, Taiwan.

Received: 15 June 2019 Accepted: 15 July 2019

Published online: 19 July 2019

\section{References}

1. Fiore AE, Fry A, Shay D, Gubareva L, Bresee JS, Uyeki T. Centers for Disease Control and Prevention (CDC). Antiviral agents for the treatment and chemoprophylaxis of influenza --- recommendations of the Advisory Committee on Immunization Practices (ACIP) MMWR Surveill Summ. 2011;60:1-24.

2. Rothberg MB, Haessler SD, Brown RB. Complications of viral influenza. Am J Med. 2008 Apr;121(4):258-64.

3. Simonsen L, Fukuda K, Schonberger LB, Cox NJ. The impact of influenza epidemics on hospitalizations. J Infect Dis. 2000;181:831-7.

4. Bridges CB, Fukuda K, Uyeki TM, Cox NJ, Singleton JA, Centers for Disease Control and Prevention, advisory committee on immunization practices. Prevention and control of influenza. Recommendations of the advisory committee on immunization practices (ACIP). MMWR Recomm Rep. 2002;51:1-31.

5. Bone RC, Balk RA, Cerra FB. Definitions for sepsis and organ failure and guidelines for the use of innovative therapies in sepsis. The ACCP/SCCM consensus conference committee. American College of Chest Physicians/ Society of Critical Care Medicine. Chest. 1992;101(6):1644-55.

6. Taubenberger JK, Morens DM. The pathology of influenza virus infections. Ann Rev Pathol Mech Dis. 2008;3:499-522.

7. Chung JY, Hsu CC, Chen JH, et al. Shock index predicted mortality in geriatric patients with influenza in the emergency department. Am J Emerg Med. 2018 May 29. pii: S0735-6757(18)30439-X.

8. Huang CC, Kuo SC, Chien TW, Lin HJ, Guo HR, Chen WL, Chen JH, Chang SH, Su SB. Predicting the hyperglycemic crisis death (PHD) score: a new decision rule for emergency and critical care. Am J Emerg Med. 2013;31:830-4.

9. Chung MH, Huang CC, Vong SC, Yang TM, Chen KT, Lin HJ, Chen JH, Su SB, Guo HR, Hsu CC. Geriatric fever score: a new decision rule for geriatric care. PLoS One. 2014;9:e110927.

10. Chung MH, Chu FY, Yang TM, Lin HJ, Chen JH, Guo HR, Vong SC, Su SB, Huang CC, Hsu CC. Hypotension, bedridden, leukocytosis, thrombocytopenia and elevated serum creatinine predict mortality in geriatric patients with fever. Geriatr Gerontol Int. 2015;15:834-9.

11. Sankaran P, Kamath AV, Tariq SM, Ruffell H, Smith AC, Prentice $P$, Subramanian DN, Musonda P, Myint PK. Are shock index and adjusted shock index useful in predicting mortality and length of stay in community-acquired pneumonia? Eur J Intern Med. 2011;22:282-5.

12. Huang CC, Hsu CC, Guo HR, Su SB, Lin HJ. Dengue fever mortality score: a novel decision rule to predict death from dengue fever. J Inf Secur. 2017;75:532-40.

13. Andaluz D, Ferrer R. SIRS, qSOFA, and organ failure for assessing sepsis at the emergency department. J Thorac Dis. 2017 Jun;9(6):1459-62. 
14. Williams JM, Greenslade JH, McKenzie JV, et al. Systemic inflammatory response syndrome, quick sequential organ function assessment, and organ dysfunction: insights from a prospective database of ED patients with infection. Chest. 2017 Mar;151(3):586-96.

15. Wester AL, Dunlop O, Melby KK, et al. Age-related differences in symptoms, diagnosis and prognosis of bacteremia. BMC Infect Dis. 2013;13:346.

16. Freund $\mathrm{Y}$, Lemachatti N, Krastinova E, et al. Prognostic accuracy of sepsis-3 criteria for in-hospital mortality among patients with suspected infection presenting to the emergency department. JAMA. 2017;317(3):301-8.

17. Sprung CL, Sakr Y, Vincent JL, et al. An evaluation of systemic inflammatory response syndrome signs in the Sepsis occurrence in acutely ill patients (SOAP) study. Intensive Care Med. 2006;32:421-7.

18. Pierrakos C, Vincent JL. Sepsis biomarkers: a review. Crit Care. 2010;14:R15.

19. Girard TD, Opal SM, Ely EW. Insights into severe sepsis in older patients: from epidemiology to evidence-based management. Clin Infect Dis. 2005;40:719-27.

20. Chung JY, Hsu CC, Chen JH, et al. Geriatric influenza death (GID) score: a new tool for predicting mortality in older people with influenza in the emergency department. Sci Rep. 2018 Jun 18;8(1):9312.

21. Mamas MA, Fraser D, Neyses L. Cardiovascular manifestations associated with influenza virus infection. Int J Cardiol. 2008;130:304-9.

22. Danai PA, Moss M, Mannino DM, Martin GS. The epidemiology of sepsis in patients with malignancy. Chest. 2006;129:1432-40.

23. Gröndahl B, Puppe W, Weigl J, Schmitt HJ. Comparison of the BD Directigen flu a+B kit and the Abbott TestPack RSV with a multiplex RT-PCR ELISA for rapid detection of influenza viruses and respiratory syncytial virus. Clin Microbiol Infect. 2005:11:848-50.

24. Chartrand C, Pai M. How accurate are rapid influenza diagnostic tests? Expert Rev Anti-Infect Ther. 2012;10:615-7.

\section{Publisher's Note}

Springer Nature remains neutral with regard to jurisdictional claims in published maps and institutional affiliations.

Ready to submit your research? Choose BMC and benefit from:

- fast, convenient online submission

- thorough peer review by experienced researchers in your field

- rapid publication on acceptance

- support for research data, including large and complex data types

- gold Open Access which fosters wider collaboration and increased citations

- maximum visibility for your research: over $100 \mathrm{M}$ website views per year

At $\mathrm{BMC}$, research is always in progress.

Learn more biomedcentral.com/submissions 